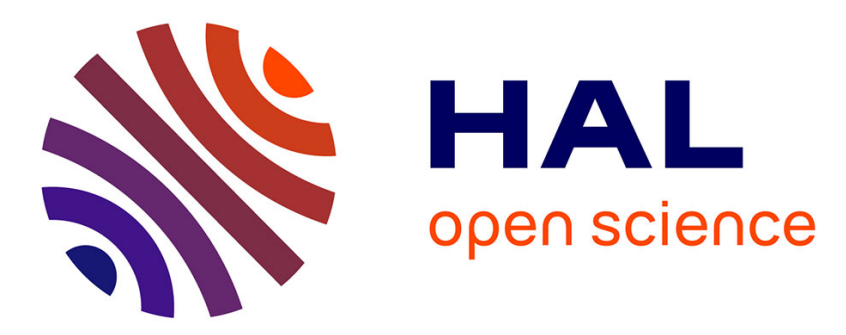

\title{
Alternative Estimators of Cointegrating Parameters in Models with Non-Stationary Data: An Application to US Export Demand
}

Paul Turner, Jim Forest

\section{- To cite this version:}

Paul Turner, Jim Forest. Alternative Estimators of Cointegrating Parameters in Models with NonStationary Data: An Application to US Export Demand. Applied Economics, 2011, 45 (05), pp.629636. 10.1080/00036846.2011.608647 . hal-00740350

\author{
HAL Id: hal-00740350 \\ https://hal.science/hal-00740350
}

Submitted on 10 Oct 2012

HAL is a multi-disciplinary open access archive for the deposit and dissemination of scientific research documents, whether they are published or not. The documents may come from teaching and research institutions in France or abroad, or from public or private research centers.
L'archive ouverte pluridisciplinaire HAL, est destinée au dépôt et à la diffusion de documents scientifiques de niveau recherche, publiés ou non, émanant des établissements d'enseignement et de recherche français ou étrangers, des laboratoires publics ou privés. 


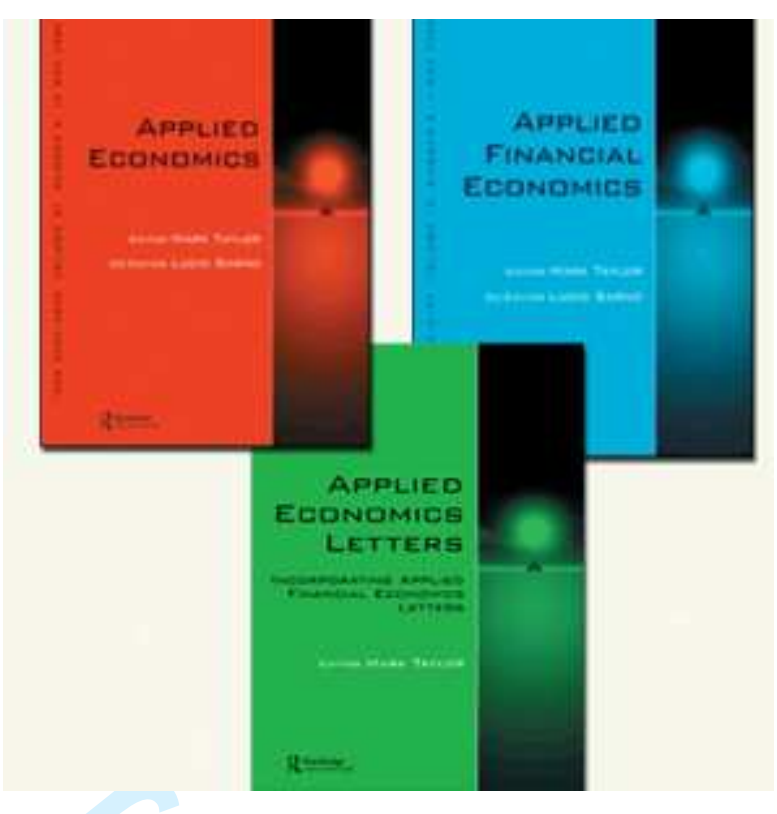

\section{Alternative Estimators of Cointegrating Parameters in Models with Non-Stationary Data: An Application to US Export Demand}

\begin{tabular}{|c|c|}
\hline Journal: & Applied Economics \\
\hline Manuscript ID: & APE-2011-0155.R1 \\
\hline Journal Selection: & Applied Economics \\
\hline $\begin{array}{r}\text { Date Submitted by the } \\
\text { Author: }\end{array}$ & 19-Jul-2011 \\
\hline Complete List of Authors: & $\begin{array}{l}\text { Turner, Paul; Loughborough University, Economics } \\
\text { Forest, Jim; University of Massachussetts }\end{array}$ \\
\hline JEL Code: & $\begin{array}{l}\text { C12 - Hypothesis Testing < C1 - Econometric and Statistical } \\
\text { Methods: General < C - Mathematical and Quantitative Methods, } \\
\text { C15 - Statistical Simulation Methods } \mid \text { Monte Carlo Methods < C1 - } \\
\text { Econometric and Statistical Methods: General }<\text { C - Mathematical } \\
\text { and Quantitative Methods }\end{array}$ \\
\hline Keywords: & $\begin{array}{l}\text { DOLS estimator, Bewley transformation, Superconsistency, US } \\
\text { Exports }\end{array}$ \\
\hline
\end{tabular}




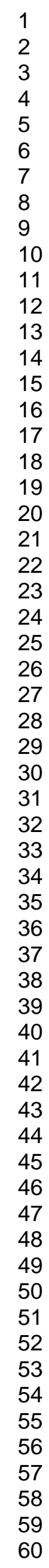

\section{SCHOLARONE ${ }^{m}$ \\ Manuscripts}

7

25

26

27

29

30

32

33

34

35

36

37

39

40

41

42

44

45

46

47

48

49

51

52

53

54

56

57

58

60

Editorial Office, Dept of Economics, Warwick University, Coventry CV4 7AL, UK 


\title{
Alternative Estimators of Cointegrating Parameters in Models
} with Non-Stationary Data: An Application to US Export Demand

\author{
Jim Forest* and Paul Turner** \\ *University of Massachussetts, Amherst, MA, USA \\ ** Department of Economics, Loughborough University, Loughborough, UK.
}

\begin{abstract}
This paper presents Monte Carlo simulations which compare the empirical performance of two alternative single equation estimators of the equilibrium parameters in a dynamic relationship. The estimators considered are Stock and Watson's dynamic ordinary least squares (DOLS) estimator and Bewley's transformation of the general autoregressive distributed lag model. The results indicate that the Bewley transformation produces a lower mean-square error as well as superior serial correlation properties even with lower truncation lags for the lagged variables included in the estimation equation. An application is then provided which examines the nature of the equilibrium relationship between aggregate US exports, world trade and the US real exchange rate. This confirms that estimation of the equilibrium parameters of this relationship by the Bewley transformation produces results which are superior to estimation by DOLS.
\end{abstract}

Keywords: DOLS estimator, Bewley transformation.

JEL Classification: $\mathrm{C} 12$, C15

Correspondence Address:

Dr Paul Turner

Department of Economics

Loughborough University

Loughborough

LE11 3TU

Tel: (44) 1509222722

Fax: (44) 1509223910

E-mail: p.m.turner@lboro.ac.uk 


\section{Introduction}

In recent years Dynamic Ordinary Least Squares (DOLS) estimator introduced by Stock and Watson (1993) has become a popular method for the estimation of equilibrium parameters in dynamic relationships between variables containing unit roots. The estimator has a number of features in common with an earlier estimator proposed by Bewley (1979). Despite the fact that Bewley's estimator (or the 'Bewley transformation' as it is popularly known) was introduced prior to the development of an extensive literature on the implications of unit roots in econometrics, it can be argued that it has a number of properties which make its performance superior to that of the DOLS estimator. It is the opinion of the current authors that the Bewley estimator has been unjustly neglected and, in support of this opinion, this paper presents a comparison of its properties relative to that of the DOLS estimator which is intended to demonstrate why it should be given more prominence in the applied econometrics literature.

In this paper Monte Carlo simulations are presented which compare the empirical performance of the Bewley transformation and the DOLS estimator. The results indicate that the Bewley transformation produces a lower mean-square error as well as superior serial correlation properties even with lower truncation lags for the lagged variables included in the estimation equation. An application is then provided which examines the nature of the equilibrium relationship between aggregate US exports, world trade and the US real exchange rate. This confirms that estimation of the equilibrium parameters of this relationship by the Bewley transformation produces results which are superior to estimation by DOLS.

The plan of the paper is as follows: In section II some statistical issues relating to the DOLS estimator and the Bewley transformation are investigated. It is then demonstrated that both these estimators are superconsistent when the data series in the equilibrium 
relationship contain a unit root. However, it is also demonstrated that the Bewley transformation is necessarily biased in small samples because of the non-zero covariance of the current change in the dependent variable and the error term. In section III the data generation process for a Monte Carlo investigation of the properties of these estimators is set out and simulations are presented for a variety of scenarios. This is followed in section IV by an application of the methodology to an equilibrium relationship between aggregate US exports, world trade and the US real exchange rate. Finally, in section V the conclusions of the paper are presented.

\section{Consistency of the DOLS estimator}

It has long been recognised that, even though OLS estimation of non-dynamic relationships will provide superconsistent estimates of long-run parameters, there are significant problems with such an approach when dealing with finite data sets and complex dynamic relationships. A standard approach to the recovery of long-run parameters from such models was to estimate an error-correction model and use its parameters to calculate the parameters of interest. This approach was set out by Bardsen (1989) and a recent comparison of its use with simple OLS estimates can be found in Cook (2008). More recently however, the dynamic ordinary least squares (DOLS) estimator has become a popular method within the literature. This estimator has been popularised by Stock and Watson (1993), building on earlier work by Saikkonen (1991), and has since become established throughout the applied econometrics literature. Examples of its use can be found in Masih and Masih (1996), Agarwal (2001), Konno and Fukushige (2003), Narayan (2004) and Narayan and Narayan (2005). Recently it has also been used extensively in the estimation of equilibrium parameters in dynamic panel models as in Auteri and Constantini (2004) and Harb (2005 and 2007).

The DOLS estimator takes the form: 


$$
y_{t}=\gamma_{1} x_{t}+\sum_{j=-k}^{k} \gamma_{j+k+2} \Delta x_{t+j}+u_{t}
$$

where $y$ and $x$ are integrated series of the same order and $u$ is a stationary random error. The parameter $\gamma_{1}$ measures the equilibrium or long-run response of $y$ to $x$ and the $\Delta x$ terms capture the short-run relationship between the variables. The truncation lag $k$ is chosen so that the errors are white-noise.

The nature of the DOLS estimator can be illustrated using the example of the finite distributed lag model (cf. Hendry (1995)). This takes the form:

$$
y_{t}=\beta_{1} x_{t}+\beta_{2} x_{t-1}+u_{t}
$$

where $x$ is a weakly exogenous random variable and $u$ is a random error with the standard Gaussian properties. This can easily be reparameterised to the DOLS format of:

$$
y_{t}=\gamma_{1} x_{t}+\gamma_{2} \Delta x_{t}+u_{t}
$$

where $\gamma_{1}=\beta_{1}+\beta_{2}$ is the long-run elasticity of $y$ with respect to $x$. The DOLS estimator of $\gamma_{1}$ can be derived as:

$$
\hat{\gamma}_{1}=\frac{\sum x_{t} y_{t}}{\sum x_{t}^{2}-\frac{\left(\sum x_{t} \Delta x_{t}\right)^{2}}{\sum\left(\Delta x_{t}\right)^{2}}}-\frac{\sum x_{t} \Delta x_{t} \sum \Delta x_{t} y_{t}}{\sum x_{t}^{2} \sum\left(\Delta x_{t}\right)^{2}-\left(\sum x_{t} \Delta x_{t}\right)^{2}}
$$


Now if $x$ is an $I(1)$ process, it follows that $\sum x_{t}^{2}$ and $\sum x_{t} y_{t}$ are $O\left(T^{2}\right)$ while $\sum x_{t} \Delta x_{t}$, $\sum \Delta x_{t} y_{t}$ and $\sum\left(\Delta x_{t}\right)^{2}$ are $O(T)$. Thus, as the sample size gets large, the DOLS estimator converges on $\hat{\gamma}_{1}=\frac{\sum x_{t} y_{t}}{\sum x_{t}^{2}}$ which is just the OLS estimator for a simple regression of $y$ on $x$. By standard results, the simple OLS estimator is super-consistent under these assumptions and therefore the DOLS is also super-consistent. Superconsistency means that the estimator converges on the true value at a faster rate than would be the case for stationary series because of the non-stationary nature of the data in the regression equation. More formally, we have $\hat{\gamma}_{1}-\gamma_{2}=O\left(T^{-1}\right)$ for series with a single unit root while $\hat{\gamma}_{1}-\gamma_{2}=O\left(\sqrt{T}^{-1}\right)$ for stationary data, i.e. the estimation error tends to zero at a rate given by $1 / T$ for $I(1)$ series but at rate $1 / \sqrt{T}$ for $I(0)$ series.

The super-consistency property of the DOLS estimator arises because of the reparameterisation of the original regression equation which has the effect of writing the equation so that the $y$ and $x$ variables are of a higher order of integration than the other variables in the relationship. However, this is also be true of the simple regression equation which excludes $\Delta x_{t}$ from the right hand side. The DOLS formulation is only superior to simple OLS regression (or other similar estimators) if either (a) it has lower small sample bias or (b) the convergence to the long-run value is faster. These questions can be addressed theoretically as in the work of Stock and Watson (1993) but they can also be investigated empirically through the use of Monte Carlo simulations.

The standard DOLS estimator (1) includes lags of the $\Delta x$ process but not lags of $\Delta y$. However, there are important cases in which lags of $\Delta y$ arise naturally. Unfortunately this creates econometric problems because $\Delta y_{t}$ will be correlated with $u_{t}$, meaning that a DOLS estimator which includes $\Delta y_{t}$ will suffer from small-sample bias. More interesting 
however, is whether this bias disappears quickly as suggested by the super-consistency property. Consider the standard partial adjustment model given by equation (5):

$$
y_{t}=\beta_{1} x_{t}+\beta_{2} y_{t-1}+u_{t}
$$

This can also be reparameterised to yield:

$$
y_{t}=\gamma_{1} x_{t}+\gamma_{2} \Delta y_{t}+u_{t}
$$

where $\gamma_{1}=\frac{\beta_{1}}{1-\beta_{2}}$ is the long-run elasticity of $y$ with respect to $x$. However, in this case $\operatorname{cov}\left(\Delta y_{t}, u_{t}\right)=\sigma_{u}^{2}$ and therefore the OLS estimator of the parameters of (6) will be biased in small samples. In large samples however, the OLS estimator can again be shown to have the super-consistency property under the assumption that $x$ is integrated of order 1 . This follows because we can write the OLS estimator of the parameter of interest as:

$$
\hat{\gamma}_{1}=\frac{\sum x_{t} y_{t}}{\sum x_{t}^{2}-\frac{\left(\sum x_{t} \Delta x_{t}\right)^{2}}{\sum\left(\Delta y_{t}\right)^{2}}}-\frac{\sum x_{t} \Delta y_{t} \sum \Delta x_{t} y_{t}}{\sum x_{t}^{2} \sum\left(\Delta y_{t}\right)^{2}-\left(\sum x_{t} \Delta y_{t}\right)^{2}}
$$

If $x$ is $I(1)$ it follows that $\sum x_{t}^{2}$ and $\sum x_{t} y_{t}$ are $O\left(T^{2}\right)$ while $\sum x_{t} \Delta y_{t}, \sum \Delta y_{t} y_{t}$ and $\sum\left(\Delta y_{t}\right)^{2}$ are $O(T)$ which means that $\hat{\gamma}_{1} \rightarrow \frac{\sum x_{t} y_{t}}{\sum x_{t}^{2}}$ as $T \rightarrow \infty$. This is again the simple OLS formula for a simple regression of $y$ on $x$ and because simple OLS is superconsistent it follows that this reparameterisation also yields super-consistent estimates. In this case however, finite sample estimates will be biased. 
The reparameterisation (6) is familiar in the applied econometrics literature. It was originally suggested by Bewley (1979). However, Bewley was writing before the literature on cointegration became established and therefore before econometricians became aware of the super-consistency property. The emphasis in this paper is on the need to allow for the endogeneity of the right-hand side variable $\Delta y_{t}$ which is introduced by the transformation. Bewley suggests the use of an instrumental variable estimator where $\Delta y_{t}$ is instrumented by $y_{t-1}$ and this can be shown to yield consistent estimates even in the case where $x$ and $y$ are $I(0)$ variables. As with any instrumental variable estimator, there is a trade-off between bias and efficiency. In the case of integrated variables, where the bias disappears as the sample size gets larger, the use of an IV estimator may produce inferior results in terms of the mean square error. However, this is again an issue which can usefully be investigated using Monte Carlo methods. The aim in this paper is to use such methods to compare the statistical performance of the DOLS estimator and the Bewley transformation .

A final issue concerning the DOLS estimator is the role of 'leads' in the DOLS regression equation. Stock and Watson (1993) argue that the leads of $\Delta x$ in equation (1) allow for feedback in cases where $x$ is Granger caused by $y$. In a recent paper Hayakawa and Kurozumi (2008) investigate the use of leads in the DOLS model and conclude that its performance can be improved significantly when the leads are excluded, provided that it is first established that $x$ is not Granger caused by $y$.

\section{Simulation results and comparison with alternative estimators}

The data generation process (DGP) used for the simulations in this paper is the same as that used by Hayakawa and Kurozumi (2008). This DGP is used partly because it forms a standard benchmark for the analysis of cointegrating relationships between variables and 
partly to facilitate comparisons with the Hayakawa and Kurozumi paper. It is specified as follows:

$$
\begin{aligned}
& y_{t}=1+x_{t}+u_{1 t} \\
& x_{t}=x_{t-1}+u_{2 t}
\end{aligned} \text { where }\left(\begin{array}{l}
u_{1 t} \\
u_{2 t}
\end{array}\right)=\left(\begin{array}{cc}
a_{11} & 0 \\
0 & a_{22}
\end{array}\right)\left(\begin{array}{l}
u_{1 t-1} \\
u_{2 t-1}
\end{array}\right)+\left(\begin{array}{l}
\varepsilon_{1 t} \\
\varepsilon_{2 t}
\end{array}\right) \text { and }\left(\begin{array}{l}
\varepsilon_{1 t} \\
\varepsilon_{2 t}
\end{array}\right) \sim \operatorname{iidN}\left(0,\left[\begin{array}{cc}
1 & \sigma_{12} \\
\sigma_{12} & 1
\end{array}\right]\right)
$$

This DGP is simulated using the EViews seeded random number generator for the normal distribution with $u_{10}=u_{20}=0$ and the first 100 observations are discarded to avoid the starting values contaminating the results. 10,000 replications are considered for each set of simulations. A non-zero value of $a_{22}$ allows for Granger causality from $y$ to $x$.

The simulations reported in this paper consider three possible strategies for the determination of the truncation lag. The first strategy involves choosing a value of $k$ which ensures that there is no residual serial correlation in the estimated equation. We attempt to ensure this by beginning with $k=0$ and then progressively increasing its value if the Ljung-Box test statistic for serial correlation up to $10^{\text {th }}$ order exceeds its critical value. In some cases this led to extremely long truncation lags and therefore a maximum value of $k$ was fixed at 10 . The two alternative criteria involve a choice of $k$ which minimises either the Akaike Information Criterion (AIC) or the Schwartz Information Criterion (SIC). We allow for four different specifications of the estimated equation. The first two are variants of the standard DOLS model (1) in which we first estimate with lags only and then allow for the possibility of lead terms for $\Delta x$. The next two specifications are variants of the Bewley transformation equation (6). In the first, we estimate using OLS, implicitly relying on the super-consistency property to generate consistent estimates when $\operatorname{cov}\left(\Delta y_{t}, u_{t}\right) \neq 0$. In the second we estimate by instrumental variables to allow for the endogeneity of the $\Delta y_{t}$ variable explicitly. Each simulation is run for a variety of different values of $a_{22}=\{0.0,0.5,0.8\}$ to estimate the effects of Granger feedback from $y$ to $x$. 
Table One presents the results for simulations in which the truncation lag is determined by the Ljung-Box test for serial correlation. The results reported for each simulation comprise the bias (average deviation of $\hat{\gamma}_{1}$ from its true value), the standard deviation, the mean square error, the average truncation lag and the percentage of the simulations in which $H_{0}: \gamma_{1}=1$ is rejected in favour of the alternative $H_{1}: \gamma_{1} \neq 1$ using the $5 \%$ critical value from the standard normal distribution. Since all the processes considered contain a unit root, we would expect that the standard normal critical values would not be appropriate. However, it is still interesting to examine the differences between the alternative models in terms of the rejection frequency. 
Table One: Simulation Results - Estimates of $\gamma$ with Truncation Lag determined by Ljung-Box Serial Correlation Test

\begin{tabular}{|c|c|c|c|c|c|}
\hline \multicolumn{6}{|c|}{ Feedback } \\
\hline 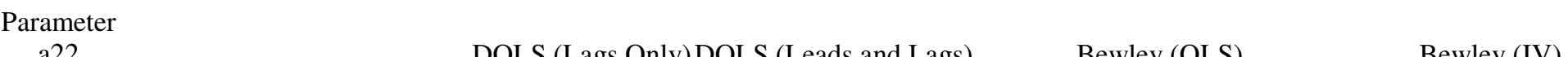 & & DOLS (Lags Only) & eads and Lags) & Bewley (OLS) & Bewley (IV) \\
\hline \multirow[t]{6}{*}{0} & Bias & 0.002064357 & 0.001911935 & 0.008929348 & 0.001948995 \\
\hline & Standard Deviation & 0.067992392 & 0.084420662 & 0.064458062 & 0.059454972 \\
\hline & MSE & 0.004627227 & 0.007130504 & 0.004234575 & 0.003538692 \\
\hline & DW Stat & 1.0903 & 1.1019 & 0.2515 & 1.9739 \\
\hline & Truncation Lag & 9 & 8.9 & 10 & 0.4 \\
\hline & $\% \mathrm{H} 0$ rejections $*$ & 24.89 & 25.11 & 58.76 & 7.11 \\
\hline \multirow[t]{6}{*}{0.5} & Bias & 0.000070174 & -0.000144475 & 0.001446276 & -0.007386494 \\
\hline & Standard Deviation & 0.035287789 & 0.043951942 & 0.033124217 & 0.031429874 \\
\hline & MSE & 0.001245233 & 0.001931794 & 0.001099305 & 0.001042397 \\
\hline & DW Stat & 1.103 & 1.1159 & 0.2502 & 1.8003 \\
\hline & Truncation Lag & 9 & 8.9 & 10 & 0.7 \\
\hline & $\% \mathrm{H} 0$ rejections & 24.81 & 25.06 & 59.31 & 12.33 \\
\hline \multirow[t]{6}{*}{0.8} & Bias & -0.000494056 & -0.000553651 & -0.001148566 & -0.007093028 \\
\hline & Standard Deviation & 0.01600721 & 0.020011418 & 0.014891499 & 0.016510089 \\
\hline & MSE & 0.000256475 & 0.000400763 & 0.000223076 & 0.000322894 \\
\hline & DW Stat & 1.1146 & 1.1288 & 0.2578 & 1.7712 \\
\hline & Truncation Lag & 8.9 & 8.7 & 10 & 0.8 \\
\hline & $\% \mathrm{H} 0$ rejections & 25.59 & 25.68 & 59.51 & 16.53 \\
\hline
\end{tabular}

* Test of $H_{0}: \gamma=1$ against $H_{1}: \gamma \neq 1$ using a 5\% critical value. Bias, Standard Deviation, MSE, DW Stat and Truncation Lag are averages over 10,000 simulated values. 
In terms of the bias and the mean square error, it is clear from Table One that all the estimators have reasonable properties in that both the bias and the mean square error are very low in absolute terms. This reflects the super-consistency property which holds when $y$ and $x$ are both unit root processes. In fact there is relatively little to choose between the estimators, though there is a tendency for the DOLS estimator with leads and lags to have a higher MSE. Interestingly the MSE tends to decline the higher is the $a_{22}$ parameter and therefore the greater the extent of Granger feedback from $y$ to $x$. However, there is no indication that the inclusion of leads improves the performance noticeably in these cases as suggested by Hayakawa and Kurozumi (2008).

The Bewley transformation with IV estimation has two advantages over the other estimators. First, it is considerably more parsimonious as shown by the lower truncation lag in all cases. For the two DOLS estimators, the truncation lags are around 9 in all cases. However, even such long truncation lags do not completely remove serial correlation as can be seen by the low values of the Durbin-Watson test statistics which indicate that first order serial correlation remains a problem in all cases. The fact that the simulations pass the Ljung-Box test has more to do with its lack of power due to the portmanteau nature of the test, and the decision to test for serial correlation up to $10^{\text {th }}$ order, rather than the ability of lags of $\Delta x$ to capture residual serial correlation. The second advantage of the Bewley transformation is that it produces rejection frequencies for $H_{0}: \gamma_{1}=1$ which are much closer to the $5 \%$ value which would be observed if the test had the correct size. The importance of using an IV estimator is indicated by the much larger truncation lags when OLS is used with the Bewley transformation as well as the higher MSE and rejection frequency. In fact the Bewley transformation, coupled with OLS estimation, produces the least satisfactory of all the simulation results as evidenced by the high MSE, the low values of the Durbin-Watson statistic and the excessive rejection frequencies for the null hypothesis $H_{0}: \gamma_{1}=1$. 
Next consider Table Two, in which the truncation lag is chosen by the process of minimising the Akaike Information Criterion. For the DOLS estimators, the truncation lags are much lower than we when use the Ljung-Box criterion. In these simulations the average $k$ is typically between 2 and 3 , as is also the case when the Bewley transformation with IV is used. The Bewley transformation with OLS estimation is again the worst performing of the four estimators with truncation lags at the maximum value of 10, low values of the Durbin-Watson statistics and high rejection frequencies for the null that the cointegrating parameter for $x$ equals its true value. The best performing estimator is again the Bewley transformation with IV estimation as evidenced by the fact that the Durbin-Watson statistics are close to 2 coupled with rejection frequencies which, while still too high, are closer to the theoretical size of the test. Table Three gives the results when the truncation lag is chosen by the Schwartz Information Criterion. The results are qualitatively very similar to the AIC results, although the truncation lags are generally lower reflecting the more parsimonious nature of the SIC. 
Table Two: Simulation Results - Estimates of $\gamma$ with Truncation Lag determined by Akaike Information Criterion

\begin{tabular}{|c|c|c|c|c|c|}
\hline \multicolumn{6}{|c|}{ Feedback } \\
\hline Parame & & & & & \\
\hline $\mathrm{a} 22$ & & DOLS (Lags Only) & eads and Lags) & Bewley (OLS) & Bewley (IV) \\
\hline 0 & Bias & 0.00384808 & 0.005710912 & 0.008935709 & 0.002177571 \\
\hline & Standard Deviation & 0.060481625 & 0.063711014 & 0.0644623 & 0.059990239 \\
\hline & MSE & 0.003672835 & 0.004091708 & 0.004235235 & 0.003603571 \\
\hline & DW Stat & 1.0835 & 1.0858 & 0.2514 & 1.9824 \\
\hline & Truncation Lag & 2.5 & 2.2 & 10 & 1 \\
\hline & $\% \mathrm{H} 0$ rejections & 25.65 & 26.38 & 58.77 & 7.39 \\
\hline 0.5 & Bias & 0.000119103 & 0.000137337 & 0.001449597 & 0.000477436 \\
\hline & Standard Deviation & 0.029992372 & 0.030879353 & 0.033132893 & 0.030874223 \\
\hline & MSE & 0.000899557 & 0.000953553 & 0.00109989 & 0.000953446 \\
\hline & DW Stat & 1.0934 & 1.0946 & 0.2499 & 1.9752 \\
\hline & Truncation Lag & 1.3 & 1.2 & 10 & 1.0 \\
\hline & $\% \mathrm{H} 0$ rejections & 25.06 & 25.16 & 59.33 & 7.85 \\
\hline 0.8 & Bias & -0.000792338 & -0.001125289 & -0.001150984 & -0.000288335 \\
\hline & Standard Deviation & 0.014098662 & 0.014767737 & 0.014890968 & 0.013830719 \\
\hline & MSE & 0.0001994 & 0.000219352 & 0.000223066 & 0.000191372 \\
\hline & DW Stat & 1.1058 & 1.1082 & 0.2575 & 1.9818 \\
\hline & Truncation Lag & 2.4 & 2.2 & 10 & 1.0 \\
\hline & $\% \mathrm{H} 0$ rejections & 26.01 & 26.34 & 59.51 & 8.26 \\
\hline
\end{tabular}


Table Three: Simulation Results - Estimates of $\gamma$ with Truncation Lag determined by Schwartz Information Criterion

$\begin{array}{cl}\begin{array}{c}\text { Feedback } \\ \text { Parameter } \\ \text { a22 }\end{array} & \\ 0 & \\ & \\ & \text { Bias } \\ & \text { Standard Deviation } \\ & \text { MSE } \\ & \text { DW Stat } \\ & \text { Truncation Lag } \\ & \text { \% H0 rejections } \\ & \\ 0.5 & \text { Bias } \\ & \text { Standard Deviation } \\ & \text { MSE } \\ & \text { DW Stat } \\ & \text { Truncation Lag } \\ & \% \text { H0 rejections } \\ & \\ 0.8 & \text { Bias } \\ & \text { Standard Deviation } \\ & \text { MSE } \\ & \text { DW Stat } \\ & \text { Truncation Lag } \\ & \text { \% H0 rejections }\end{array}$

\author{
DOLS (Lags Only) DOLS (Leads and Lags)
}

$\begin{array}{rr}0.007264562 & 0.010274228 \\ 0.05937801 & 0.060451518 \\ 0.003578522 & 0.003759946 \\ 1.0826 & 1.0828 \\ 1.8 & 1.4 \\ 25.86 & 26\end{array}$

0.000200279

0.029656667

0.000879558

1.0929

24.82

$-0.001497444$

0.01389029

0.000195183

1.1043

1.8

25.98

\subsection{5}

0.030227026

0.000913711

1.0941

1

24.76

$-0.002070976$

0.014198143

0.000205876

1.1051

1.4
26.11
Bewley (OLS)

0.009875948

0.063979632

0.004190928

0.2483

9.1

58.6

0.001624559

0.032741218

0.001074627

0.2464

9

58.67

$-0.001223095$

0.014747346

0.00021898

0.2543

9.1
58.91
Bewley (IV)

0.002169948

0.060012366

0.003606193

1.9824

1.0

7.41

0.000473153

0.030893838

0.000954653

1.9751

1.0
7.88

7.88

$-0.000287102$

0.013838305

0.000191581

1.9815

1.0
8.33 


\title{
IV. Example: US Export Demand 1978q4 to 2005q4
}

\begin{abstract}
As an example of the relative performance of the DOLS methodology and the Bewley procedure, this section presents the results from estimation of an equation for exports in the US economy over the period $1978 \mathrm{q} 4$ to $2005 q 4$. The equation relates the US\$ value of US exports at constant 2000 prices to the total exports of the five large industrial economies (France, Germany, Italy, UK and Japan) also measured in US\$ at 2000 prices as well as the real effective exchange rate (measured on a relative unit labour cost basis). The three variables used as the basis of the equation are shown in Figure 1 with each variable being expressed in logarithmic form. All data are taken from the IMF International Financial Statistics database.
\end{abstract}


$\operatorname{LOG}(X)$

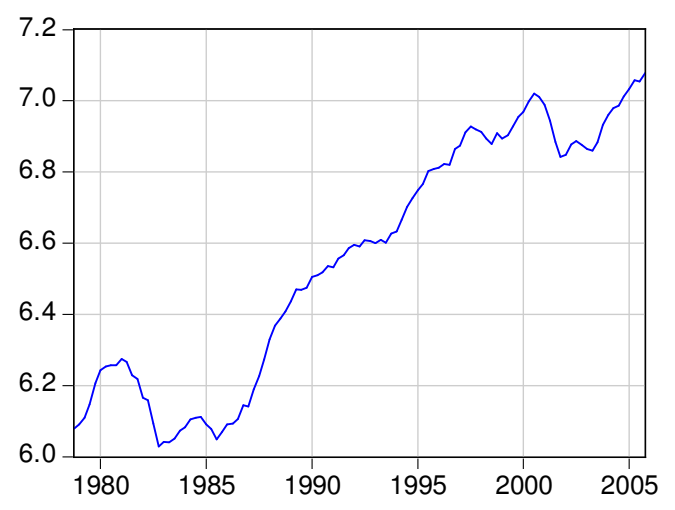

LOG(IEXPSA)

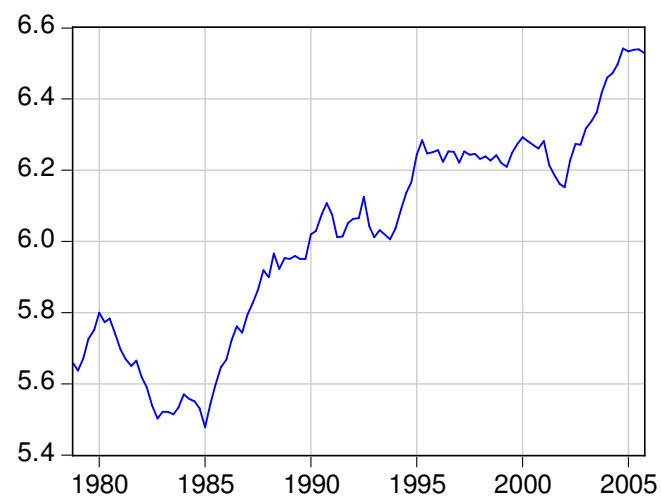

LOG(REER)

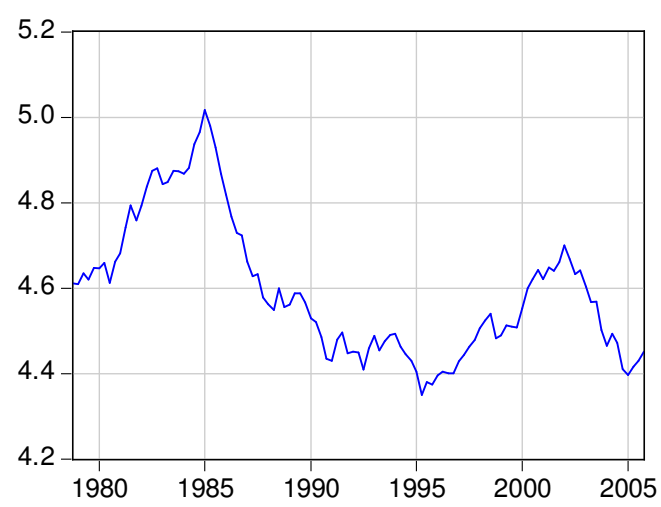

Figure 1: US export model variables $-X=U S$ exports, IEXPSA = Total Exports of France, Germany, Italy, UK and Japan, REER = real effective exchange rate (relative unit labour cost basis.

Preliminary data analysis shows that each of the variables contains a unit root. Application of the Johansen cointegration test yields a trace statistic of 29.69 and a maximum eigenvalue statistic of 24.72 which compare with $5 \%$ critical values of 31.88 and 21.49 respectively. Thus the evidence for a cointegrating vector is mixed with the trace test (only just) failing to reject the null of no cointegrating vectors while the maximum eigenvalue test rejects. On this basis it was thought reasonable to assume that a 
cointegrating relationship exists and that the DOLS and Bewley estimates could be interpreted as methods for the estimation of the parameters of this vector.

Next, the parameters of the equilibrium relationship are estimated using both the DOLS procedure and the Bewley transformation. The results of the DOLS procedure are given in equation (8). A truncation lag of 4 was chosen on the basis that this minimises the Schwartz criterion. The coefficient estimates for the lags and leads of the differenced explanatory variables are not reported because these are of no direct interest. Standard errors are given in parentheses below coefficients.

Equation (8) yields estimates of the long-run elasticities of US exports with respect to world trade and the real exchange rate of 1.23 and 0.15 respectively. The estimate of the world trade elasticity is considerably above one and, on the basis of a conventional $t$ test would be significantly greater than one. The estimate of the real exchange rate elasticity has the 'wrong' sign in that economic theory would suggest a negative effect and is moreover statistically significant when we use a $t$-test. However, the $t$-test is not appropriate here because the equation is badly dynamically misspecified. A truncation lag of 4 is clearly not sufficient to produce residuals which are serially uncorrelated as evidenced by the Durbin-Watson and Breusch-Godfrey test statistics. Moreover, extending the truncation lag does little to eliminate serial correlation. Truncation lags of up to 10 were tried with little change in either of the test statistics for serial correlation. The equation also shows clear evidence of misspecification in the form of a significant first-order ARCH process in the residuals as well as a significant Jarque-Bera test for non-normality. In summary, the DOLS procedure may give unbiased estimates of the long-run elasticities but there is little else to recommend it since it produces a badly misspecified equation when estimated. 


$$
\begin{aligned}
\ln X_{t}= & -\underset{(0.3578)}{1.5288}+\underset{(0.0247)}{1.2306} \ln W_{t}+\underset{(0.0492)}{0.1508 \ln E_{t}} \\
& +\sum_{i=0}^{4} \hat{\gamma}_{i} \Delta W_{t-i}+\sum_{i=1}^{4} \hat{\gamma}_{i+4} \Delta W_{t+i}+\sum_{i=0}^{4} \hat{\phi}_{i} \Delta E_{t-i}+\sum_{i=1}^{4} \hat{\phi}_{i+4} \Delta W_{t+i}+\hat{u}_{t}
\end{aligned}
$$

$$
D W=0.3718 \quad J B=7.43(0.024) \quad \hat{\sigma}=0.041908
$$$$
B G_{4}=38.44(0.00) \quad A R C H=157.44(0.00)
$$

$D W$ is the Durbin-Watson statistic, JB is the Jarque Bera statistic for non-normality of the residuals which is distributed as $\chi^{2}(2)$ under the null of normal residuals, $\hat{\sigma}$ is the standard error of the regression, $B G_{4}$ is the $\chi^{2}$ form of the Breusch-Godfrey test for $4^{\text {th }}$ order serial correlation and $\mathrm{ARCH}$ is the $\chi^{2}$ form of the Lagrange Multiplier test for first order autoregressive conditional heteroscedasticity in the residuals. Pvalues are given in parentheses next to test statistics.

Next, an equilibrium relationship was estimated using the Bewley transformation. Again, the Schwartz criterion was used to determine the truncation lag for the number of differenced variables and this produced a truncation lag of zero in this case, i.e. the current value of each of the differences. The results are reported in equation (9) which was estimated by the method of instrumental variables using $\ln X_{t-1}$ as an instrument for the endogenous right-hand side variable $\Delta \ln X_{t}$.

$$
\begin{aligned}
& \ln X_{t}=1.8315+1.0540 \ln W_{t}-0.3398 \ln E_{t} \\
& \text { (1.3251) (0.0873) (0.1903) } \\
& +\hat{\gamma}_{1} \Delta \ln X_{t}+\hat{\phi}_{1} \Delta \ln W_{t}+\hat{\eta}_{1} \Delta \ln E_{t}+\hat{u}_{t} \\
& D W=1.7821 \quad J B=0.32(0.85) \quad \hat{\sigma}=0.01719 \\
& B G_{4}=3.70(0.44) \quad A R C H=0.0432(0.84)
\end{aligned}
$$

The estimates of the long-run elasticities given in equation (9) are closer to what would be expected from economic theory. The estimate of the world trade elasticity is 1.05 which is well within two standard errors of one (even given the likely downward bias of the standard errors). The estimate of the real exchange rate elasticity has the expected 
sign, and is reasonable in magnitude, but is not significantly different from zero when a $t$ test is used. The most important difference between the two equations we have estimated however, can be seen in the misspecification tests. For example, the Durbin-Watson and Breusch-Godfrey tests for equation (9) both indicate that it is not possible to reject the null hypothesis that the residuals are serially uncorrelated. In addition there is no evidence of an ARCH process or of non-normality in the residuals. Thus equation (9) appears to be a statistically well specified equation whereas equation (8) is clearly badly misspecified.

A comparison of the two methods therefore confirms that it is much easier to obtain a well-specified, parsimonious equation using the Bewley transformation than using the DOLS methodology. Monte Carlo analysis indicates that even with the Bewley transformation, it remains the case that the distribution of the long-run coefficient estimates is non-standard. However, the distribution is much closer the $t$ or normal distribution than would be the case for the dynamically misspecified DOLS equation. This can be useful when testing hypotheses of interest. For example, in equation (9) if the hypothesis of interest is $H_{0}: \beta_{2}=1$, where $\beta_{2}$ is the long-run elasticity of US exports with respect to world trade, the Monte Carlo analysis shows us that the standard errors are probably biased downwards slightly. Therefore the fact that the null hypothesis cannot be rejected at the usual 5\% significance level adds to our confidence that this is a reasonable restriction. In contrast that fact that the same null can be rejected, when the DOLS model is used, tells us nothing because the misspecification leads to such biased estimates of the standard errors that it is almost inevitable that the null will be rejected in this case.

\section{Conclusions}

This paper has investigated alternative single equation estimation methods for cointegrating parameters. All the methods investigated produce generally low bias and MSE which reflects the fact that all these methods will produce super-consistent 
estimates when applied to non-stationary data. Although the DOLS method is widely used in the current applied econometric literature, our results indicate that the Bewley transformation estimated using instrumental variables produces better results in terms of slightly lower MSE and noticeably better serial correlation properties. An applied example, which relates the demand for US exports to the level of industrial country exports and the US real effective exchange rates, has been estimated and presented. This indicates that the Bewley transformation produces more plausible estimates of the parameters of interest (the long-run elasticities) as well as producing a statistically well specified equation which is considerably more parsimonious. Therefore, both the Monte Carlo analysis and the example are consistent with the argument that the Bewley transformation provides a more satisfactory method for the estimation of long-run parameters in a dynamic model. 


\section{References}

Agarwal, P. (2001) The relation between savings and growth: cointegration and causality evidence from Asia, Applied Economics, 33, 499-513.

Auteri, M. and Constantini, M. (2004) Is social protection a necessity or a luxury good? new multivariate cointegration panel data results, Applied Economics, 36, 1887-1898.

Bardsen, G. (1989) Estimation of long run coefficients in error correction models, Oxford Bulletin of Economics and Statistics, 51, 345-350.

Bewley, R. A. (1979) The direct estimation of the equilibrium response in a linear model, Economics Letters, 3, 375-381.

Cook, S. (2008) Econometric analysis of interest rate pass-through, Applied Financial Economics Letters, 4, 249-251.

Harb, N. (2005) Import demand in heterogeneous panel setting, Applied Economics, 37, 2407-2415.

Harb, N. (2007) Trade between Eurozone and Arab countries: a panel study, Applied Economics, 39, 2099-2107.

Hayakawa, K. and Kurozumi, E. (2008) The role of "leads" in the dynamic OLS estimation of cointegrating regression models, Mathematics and Computers in Simulation, 79, 555-560.

Hendry, D. F. Dynamic Econometrics, Oxford University Press, Oxford, 1995.

Konno, T. and M. Fukushige (2003) Did Nafta cause the structural changes in bilateral import functions between the US and Mexico?, Journal of Policy Modeling, 25, 53-59.

Mashih, R. and Masih, A. M. M. (1996) Stock-Watson dynamic OLS (DOLS) and error correction modelling approaches to estimating long- and short-run elasticities in a demand function: new evidence and methodological implications from an application to the demand for coal in mainland China, Energy Economics, 18, 315-334.

Narayan, P. K. (2004) Do public investments crowd out private investments? Fresh evidence from Fiji, Journal of Policy Modeling, 26 , 747-753.

Narayan, P. K. and Narayan, S. (2005) Estimating income and price elasticities of imports for Fiji in a cointegration framework, Economic Modelling, 22, 423-438.

Saikkonen, P. (1991) Asymptotically efficient estimation of cointegration regressions, Econometric Theory, 7, 1-21.

Stock, J. H. and Watson, M. W. (1993) A simple estimator of cointegrating vectors in higher order integrated systems, Econometrica, 61, 783-820. 